\title{
Contribution of general practitioners and sexual health centres to sexually transmitted infection consultations in five Dutch regions using laboratory data of Chlamydia trachomatis testing
}

Citation for published version (APA):

Slurink, I. A. L., Groen, K., Gotz, H. M., Meima, A., Kroone, M. M., Hogewoning, A. A., Ott, A., Niessen, W., Dukers-Muijers, N. H. T. M., Hoebe, C. J. P. A., Koedijk, F. D. H., Kampman, C. J. G., \& van Bergen, J. E. A. M. (2020). Contribution of general practitioners and sexual health centres to sexually transmitted infection consultations in five Dutch regions using laboratory data of Chlamydia trachomatis testing. International Journal of Std \& Aids, 31(6), 517-525. [0956462420905275]. https://doi.org/10.1177/0956462420905275

Document status and date:

Published: 04/03/2020

DOI:

10.1177/0956462420905275

Document Version:

Publisher's PDF, also known as Version of record

\section{Document license:}

Taverne

\section{Please check the document version of this publication:}

- A submitted manuscript is the version of the article upon submission and before peer-review. There can be important differences between the submitted version and the official published version of record. People interested in the research are advised to contact the author for the final version of the publication, or visit the $\mathrm{DOI}$ to the publisher's website.

- The final author version and the galley proof are versions of the publication after peer review.

- The final published version features the final layout of the paper including the volume, issue and page numbers.

Link to publication

\footnotetext{
General rights rights.

- You may freely distribute the URL identifying the publication in the public portal. please follow below link for the End User Agreement:

www.umlib.nl/taverne-license

Take down policy

If you believe that this document breaches copyright please contact us at:

repository@maastrichtuniversity.nl

providing details and we will investigate your claim.
}

Copyright and moral rights for the publications made accessible in the public portal are retained by the authors and/or other copyright owners and it is a condition of accessing publications that users recognise and abide by the legal requirements associated with these

- Users may download and print one copy of any publication from the public portal for the purpose of private study or research.

- You may not further distribute the material or use it for any profit-making activity or commercial gain

If the publication is distributed under the terms of Article $25 \mathrm{fa}$ of the Dutch Copyright Act, indicated by the "Taverne" license above,

Download date: 26 Apr. 2023 


\title{
Contribution of general practitioners and sexual health centres to sexually transmitted infection consultations in five Dutch regions using laboratory data of Chlamydia trachomatis testing
}

International Journal of STD \& AIDS 2020, Vol. 3I(6) 517-525 (C) The Author(s) 2020 Article reuse guidelines: sagepub.com/journals-permissions DOI: $10.1177 / 0956462420905275$ journals.sagepub.com/home/std @SAGE

\author{
IAL Slurink' (D, K Groen², HM Gotz',3,4 (D, A Meima ${ }^{3,13}$, \\ MM Kroone ${ }^{5}$, AA Hogewoning ${ }^{5}$, A Ott ${ }^{6}$, W Niessen ${ }^{7}$, \\ NHTM Dukers-Muijers ${ }^{8,9}$, CJPA Hoebe ${ }^{8,9}$, FDH Koedijk ${ }^{10}$, \\ CJG Kampman ${ }^{10}$ and JEAM van Bergen ${ }^{1,11,12}$
}

\begin{abstract}
Effective sexually transmitted infection (STI) control requires opportunities for appropriate testing, counselling and treatment. In the Netherlands, people may attend general practitioners (GPs) and sexual health centres (SHCs; also known as STI clinics) for STI consultations. We assessed the contribution of GPs and SHCs to STI consultations in five Dutch regions with different urbanization levels, using data of urogenital Chlamydia trachomatis (CT) testing. Data (201 I2016) were retrieved from laboratories, aggregated by gender and age group (I5-24 and 25-64 years). Results show that test rates and GP contribution varied widely between regions. GP contribution decreased over time in Amsterdam (60$48 \%)$, Twente (79-61\%), Maastricht (60-50\%) and Northeast-Netherlands (82-77\%), but not in Rotterdam (65-67\%). Decreases resulted from increases in SHC test rates and slight decreases in GP test rates. GPs performed more tests for women and those aged 25-64 years compared to SHCs (relative risks ranging from I.49 to 4.76 and I.58 to 7.43, respectively). The average yearly urogenital CT positivity rate was $9.2 \%$ at GPs and $10.7 \%$ at SHCs. Overall, GPs accounted for most STI consultations, yet SHC contribution increased. Continued focus on good quality STI care at GPs is essential, as increasing demands for care can not be entirely covered by SHCs.
\end{abstract}

\section{Keywords}

Chlamydia trachomatis, general practice, primary care, epidemiology, sexual health

Date received: 7 June 2019; accepted: 20 September 2019

\footnotetext{
'Centre for Infectious Disease Control, National Institute for Public Health and the Environment (RIVM), Bilthoven, The Netherlands ${ }^{2}$ Department of Pulmonology, Interstitial Lung Diseases Center of Excellence, St Antonius Hospital, Nieuwegein, The Netherlands ${ }^{3}$ Municipal Public Health Service Rotterdam-Rijnmond, Rotterdam, The Netherlands

${ }^{4}$ Department of Public Health, Erasmus Medical Centre, Rotterdam, The Netherlands

${ }^{5}$ Department of Infectious Diseases, Municipal Public Health Service Amsterdam, Amsterdam, The Netherlands

${ }^{6}$ Department of Medical Microbiology, Certe, Groningen, The Netherlands

${ }^{7}$ Municipal Public Health Service Groningen, Groningen, The Netherlands
}

\footnotetext{
${ }^{8}$ Department of Medical Microbiology, Care and Public Health Research Institute (CAPHRI), Maastricht University Medical Centre (MUMC+), Maastricht, The Netherlands

${ }^{9}$ Department of Sexual Health, Infectious Diseases and Environmental Health, South Limburg Public Health Service, Heerlen, The Netherlands

${ }^{10}$ Public Health Service Twente, Enschede, The Netherlands

"Department of General Practice, Amsterdam University Medical Centre, Amsterdam, The Netherlands

${ }^{12}$ STI AIDS Netherlands (SOA AIDS Nederland), Amsterdam, The Netherlands

${ }^{13}$ Center for Research and Business Intelligence, Municipality of Rotterdam, Rotterdam
}

\section{Corresponding author:}

JEAM van Bergen, STI AIDS Netherlands (SOA AIDS Nederland), Amsterdam, The Netherlands.

Email: JvanBergen@soaaids.nl 


\section{Introduction}

Globally, over one million sexually transmitted infections (STIs) are acquired every day with profound impact on an individual's sexual health as well as general well-being. ${ }^{1}$ Effective STI control requires easy access to care, including appropriate diagnostics, counselling and treatment. In the Netherlands, people with STI-related questions or symptoms may consult their general practitioner (GP) or a sexual health centre (SHC; also known as an STI clinic) for an STI consultation. ${ }^{2}$ GPs are the core primary health care provider and are distributed well across the country. ${ }^{3}$ In addition to GP care, 24 SHCs, mainly coordinated by public health services (PHSs), provide free-of-charge STI consultations for high-risk groups only (e.g. persons notified for STI, having symptoms, men who have sex with men [MSM] and young people under 25). ${ }^{4}$ The limited accessibility of SHCs for people who do not belong to a high-risk group and the relative vicinity of general practices compared to SHCs mean that GPs play an essential role in STI care in the Netherlands. ${ }^{5}$

Comparison of STI testing rates and diagnoses at GPs and SHCs in the Netherlands is hampered due to notable differences in surveillance systems. ${ }^{6}$ STI consultations at GPs are estimated by extrapolating incidence rates based on routinely recorded STI-related episodes by a network of GPs in the Nivel Primary Care database. 'STI-related episodes' are the closest proxy of an STI consultation and include 'fear-ofSTI' and registered STI diagnoses, but STI tests are not registered. Although Chlamydia trachomatis (CT) infections are the most commonly diagnosed bacterial STI in the Netherlands, surveillance of CT at GPs is limited by lack of a specific code for CT in the GP network. ${ }^{7}$ In contrast, all SHC consultations and diagnoses are monitored in a national database. Both GPand SHC-collected samples are analysed by local laboratories, which register gender, age and anatomical test location of each sample. Therefore, laboratory data may provide an objective measure to compare test and positivity rate between both providers.

All patients attending an SHC obtain urogenital CT testing, in line with national guidelines. ${ }^{4}$ GP guidelines also recommend testing all patients presenting with STI-related questions or symptoms at least for urogenital CT, unless the incurred risk is negligible. ${ }^{8}$ Anorectal testing is advised at both settings for MSM and women reporting anal sex. All CT samples are analysed using commercially available nucleic acid amplification techniques according to standardized protocols. ${ }^{4,8}$ Hence, being tested for urogenital CT may be a valid proxy to compare STI consultations of both providers.
The primary aim of this study is to compare the contribution in the number of STI consultations of GPs and SHCs using aggregated laboratory data of urogenital CT testing. We compared trends in urogenital CT test rate and positivity by gender and age group from 2011 to 2016 in five geographical regions with different levels of urbanization. We additionally evaluated trends in anorectal CT testing by GPs and SHCs.

\section{Methods}

\section{Data collection}

Five Dutch geographical regions were included in this study covering $24 \%$ of the total Dutch population: the municipalities of Amsterdam and Rotterdam, the region of Twente, Northeast-Netherlands (N-NL, including the provinces Groningen, Friesland and Drenthe) and the municipality of Maastricht with two adjacent municipalities. The participating PHSs collected laboratory data of CT tests performed by both GPs and SHCs. Data from N-NL were directly obtained from laboratories. The aim was to include total number and positive results of urogenital and number of anorectal CT tests from 2011 to 2016. However, Rotterdam GP data of 2011 and 2016 and N-NL SHC data of 2015 could not be obtained due to issues concerning data sharing and contracts. Data were aggregated by gender and age group (15-24 and 25-64 years).

Laboratory services for an SHC are performed in one laboratory, whereas laboratory services for GPs are done by usually one larger and multiple smaller laboratories. As PHSs could not obtain data from all laboratories, it was not possible to obtain complete coverage of all CT tests performed by GPs. To be able to compare GP and SHC data, the PHSs estimated GP data coverage. ${ }^{9,10}$ We used this information to adjust the obtained number of tests to the approximate actual number of tests (number of tests divided by coverage). The coverage was 95\% in Amsterdam (seven laboratories), $90 \%$ in Rotterdam (one laboratory), $95 \%$ in N-NL (two laboratories), $80 \%$ in Twente (one laboratory) $^{9}$ and $90 \%$ in Maastricht (one laboratory). ${ }^{10}$ The laboratory data provide complete coverage of all tests performed by the SHC. Only tests of inhabitants living in the same catchment area as the GP data were extracted (based on postal code) by the PHSs (Amsterdam, Rotterdam, Twente) or laboratories (N-NL). For Maastricht, the PHS calculated that of the obtained number of tests, $60 \%$ were from clients from the defined catchment population. We excluded tests of clients not residing in the region using $60 \%$ of the total number of tests.

The aggregated laboratory data were combined with population numbers of citizens aged 15-64 years living 
in the included regions. Average population per year (2011-2016) stratified by gender and age group, number of municipalities and urbanization rate (addresses $/ \mathrm{km}^{2}$ ) per geographic region were obtained from Statistics Netherlands (CBS; http://www.cbs.nl). A description of collected data of each region is included in supplement 1 .

\section{Statistical analysis}

We presented the total number of tests and positive test results corrected for data coverage. Yearly urogenital CT test rates (number of urogenital CT tests per 10,000 inhabitants) and positivity rates (percentage of positive urogenital CT tests of total tests) were calculated for the total population and by gender and age group for each region and each provider category (GP and SHC). We calculated the anorectal CT test rate per 10,000 inhabitants and as a percentage of urogenital CT tests.

We used negative binomial regression analysis implemented in generalized additive models. We modelled time trends in test and positivity rate by provider category within each region using test year as a continuous variable. We modelled differences in test and positivity rates between provider categories in each region separately, correcting for test year (reference category: SHC). The log of total number of inhabitants (models for test rates) and total CT tests (models for positivity rates) were added to the models as offset. All analyses were stratified by gender and age group and performed in $\mathrm{R}$ (version 3.5.1).

\section{Results}

The five regions included in this study ranged from mostly rural (N-NL: 592 addresses $/ \mathrm{km}^{2}$ in 2016), to moderately urban (Twente: 1316 addresses $/ \mathrm{km}^{2}$, Maastricht: 1152 addresses $/ \mathrm{km}^{2}$ ) to highly urban (Rotterdam: 3968 addresses $/ \mathrm{km}^{2}$, Amsterdam: 6011 addresses $/ \mathrm{km}^{2}$ ). An average of 133,701 urogenital CT tests were performed each year across these regions, of which $63 \%$ was performed by GPs. The average yearly positivity rate was $9.2 \%(7724 / 84,108)$ at GPs and $10.7 \%(5303 / 49,593)$ at SHCs.

\section{Urogenital CT test rate and relative contribution of GPs}

Figure 1 shows that urogenital CT test rates and positivity differ substantially between regions and test providers. GP contribution to urogenital CT test rate decreased from 2011 to 2015/2016 in all regions, except in Rotterdam (Table 1). The relative contribution was highest in N-NL, but decreased slightly due to a decrease in GP test rate and an increase in SHC test rate (GP contribution $82 \%$ in 2011 to $77 \%$ in 2016). This decrease was also seen in Amsterdam (60\% to $48 \%$ ), Twente (79\% to $61 \%)$ and Maastricht $(61 \%$ to $50 \%$ ). In Rotterdam, GP contribution was stable over time $(65-67 \%)$ as both GP and SHC test rates increased.

In Amsterdam and Maastricht, the GP test rate was comparable to the SHC test rate, with relative risks (RRs) of $1.10(95 \%$ CI $0.93 ; 1.26)$ and 1.22 (1.04; 1.41), respectively (Table 1). In the other three regions, GPs performed more tests, with RR ranging from 2.00 $(1.93 ; 2.07)$ in Rotterdam to $4.10(3.96 ; 4.23)$ in N-NL. In all regions, GPs performed more tests for women and those aged 25-64 years compared to SHCs (RR ranging from 1.55 to $4.76 ; 1.58$ to 7.43 [both Amsterdam and N-NL], respectively). For men, only in Amsterdam the SHC provided more tests than GPs (RR 0.67), and for those aged 15-24, only in Amsterdam and Maastricht (RR 0.49 and 0.72).

\section{Urogenital CT positivity rate}

Urogenital CT positivity rates were lower at GPs compared to SHCs, with RRs ranging from 0.72 (0.64; $0.81)$ in Amsterdam to $0.90(0.84 ; 0.96)$ in Rotterdam (Table 2). Differences were most pronounced in women, with RRs ranging from $0.59(0.52 ; 0.66)$ in Amsterdam to $0.76(0.65 ; 0.88)$ in Maastricht. For men, no difference was observed in Amsterdam and Maastricht but higher positivity rates were found at GPs as compared to SHCs in the other regions (RRs ranging from $1.18[1.09 ; 1.28]$ in Twente to 1.32 [1.24; 1.39] in Rotterdam). Differences by age group were minor. SHC positivity rates increased slightly in all regions, significant in N-NL $(11.4-15.4 \% ; \mathrm{p}=0.02)$ and most evident in women. GP positivity rates increased over time in Amsterdam (5.9-7.9\%; $\mathrm{p}<.0001)$, Maastricht $(7.0-10.3 \% ; \mathrm{p}<.0001)$ and N-NL $(9.2-11.4 \% ; \mathrm{p}<.0001)$, but were stable in Rotterdam $(11.0-11.2 \%)$ and decreased in Twente $(12.6-9.4 \% ; \mathrm{p}<.0001)$.

\section{Anorectal CT test rate}

All regions except Maastricht showed an increase in anorectal CT test rate by both GPs and SHCs (Figure 2). Differences between GPs and SHCs were large, for example in Maastricht, the proportion of anorectal tests as a percentage of urogenital tests was $31.1 \%$ at the SHC, but only $0.7 \%$ at GPs. Anorectal testing at SHCs was highest among men and those aged 25-64, but at GPs these differences were less profound, except for Amsterdam (Supplement 2). 

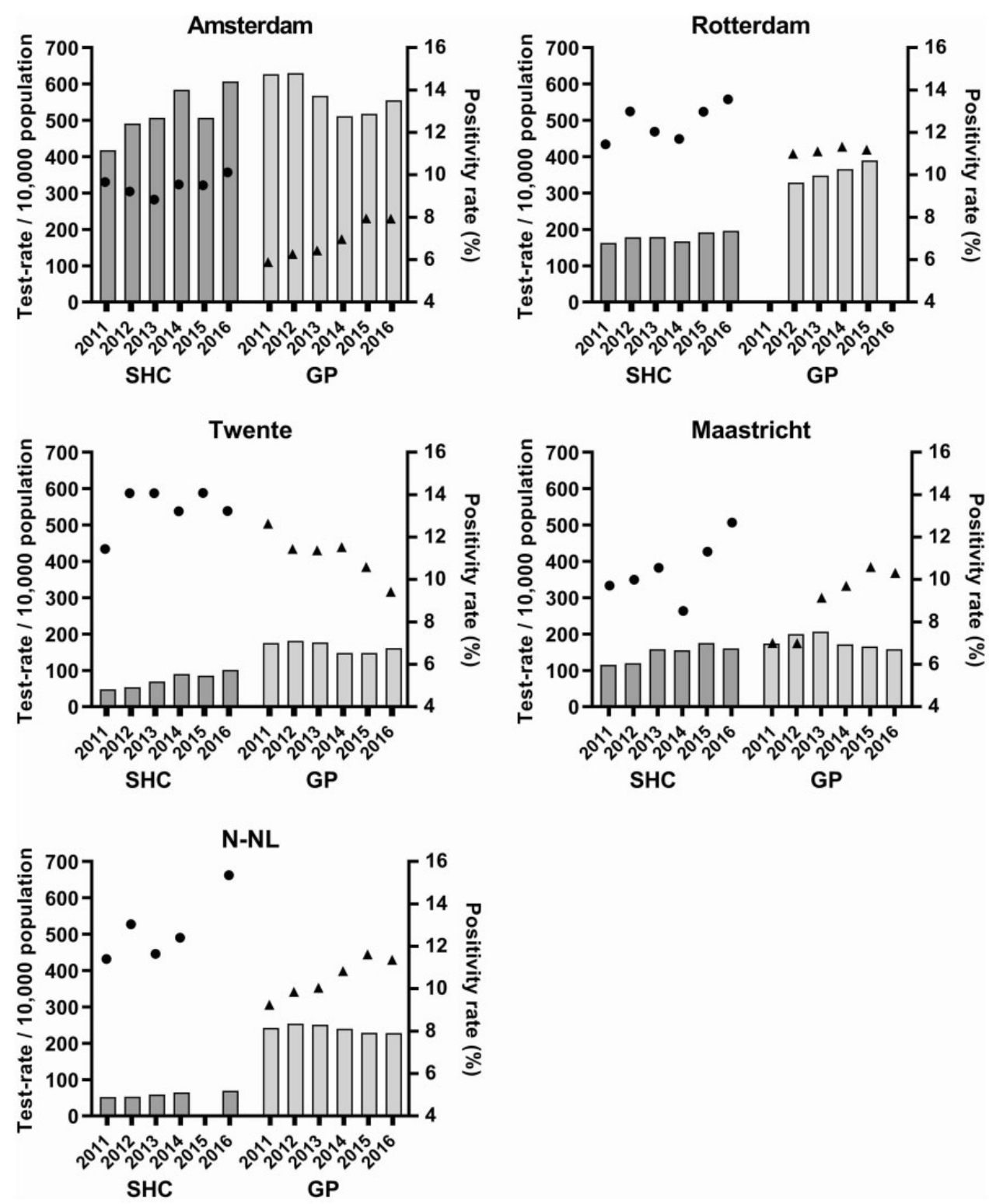

Figure I. Annual urogenital CT test rate (15-64 years of age) (bars: left axis) and urogenital CT positivity rate (percentage of urogenital CT positive tests) (points: right axis) at SHCs and GPs in five regions, 20II-20I6.

GP: general practitioner; N-NL: Northeast-Netherlands; SHC: sexual health centre.

\section{Discussion}

Our analysis of laboratory data of urogenital CT testing by GPs and SHCs in five Dutch regions showed that GPs accounted for the majority of STI consultations. GP contribution was highest in N-NL and Twente, both consisting of moderately urban to rural areas with an SHC only in the larger cities, followed by Rotterdam, a large city. In Maastricht, a smaller region, and in Amsterdam, a highly urbanized city, the SHC and GP contributed equally. GP contribution decreased in most regions except Rotterdam, while
SHCs continue to expand their services. Urogenital CT positivity rates were generally higher at SHCs as compared to GPs.

GP contribution was previously estimated at $63-70 \%$ of all consultations based on GP network and SHC data. ${ }^{2,5,6}$ Our results suggest that although this result may be valid on the national level, tests rates and provider contributions vary largely by region. SHCs play a more predominant role in urbanized cities as compared to larger, rural regions, for which a possible explanation is greater accessibility due to less travel time and convenience of transport 
Table I. Trends and difference in urogenital Chlamydia trachomatis test rates between SHCs and GPs for the total population and by gender and age group in Amsterdam, Rotterdam, Twente, Limburg and N-NL, 20II-20I6.

\begin{tabular}{|c|c|c|c|c|c|c|c|}
\hline \multirow[b]{3}{*}{ Amsterdam } & \multicolumn{2}{|l|}{$\mathrm{SHC}$} & \multicolumn{3}{|l|}{ GP } & \multicolumn{2}{|c|}{ Relative contribution GP } \\
\hline & \multicolumn{2}{|c|}{$\begin{array}{l}\text { Test rate } \\
(\mathrm{n} / 10,000)^{\mathrm{a}}\end{array}$} & \multicolumn{2}{|c|}{$\begin{array}{l}\text { Test rate } \\
(\mathrm{n} / 10,000)^{\mathrm{a}}\end{array}$} & \multirow[t]{2}{*}{$\operatorname{RR}(95 \% \mathrm{Cl})^{\mathrm{b}}$} & \multicolumn{2}{|l|}{ (\%) } \\
\hline & 2011 & 2016 & 2011 & 2016 & & 2011 & 2016 \\
\hline Total & 418 & $607^{* *}$ & 627 & $555^{*}$ & $\mathrm{I} .10(0.93 ; \mathrm{I} .26)$ & 60.0 & 47.8 \\
\hline Men & 456 & $659 * *$ & 372 & 372 & $0.68(0.57 ; 0.78)^{* * * *}$ & 44.9 & 36.1 \\
\hline Women & 380 & $555^{*}$ & 879 & $736^{*}$ & $1.55(1.34 ; 1.76)^{* * * *}$ & 69.8 & 57.0 \\
\hline $15-24$ & 949 & $1646 * * *$ & 770 & $587^{* * * *}$ & $0.49(0.21 ; 0.76)^{* * * *}$ & 44.8 & 26.3 \\
\hline $25-64$ & 309 & 393 & 597 & $549 *$ & $1.58(1.47 ; 1.69)^{* * * *}$ & 65.9 & 58.3 \\
\hline Rotterdam ${ }^{c}$ & 2011 & 2016 & 2012 & 2015 & & 2012 & 2015 \\
\hline Total & 163 & $196 * *$ & 329 & $390 * * * *$ & $2.00(1.93 ; 2.07)^{* * * *}$ & 64.9 & 67.0 \\
\hline Men & 173 & $243 * * *$ & 216 & $256 * * * *$ & $1.19(1.11 ; 1.27)^{* * * *}$ & 52.5 & 53.0 \\
\hline Women & 153 & 149 & 442 & $523 * * *$ & $3.04(2.95 ; 3.13)^{* * * *}$ & 73.4 & 76.8 \\
\hline $15-24$ & 362 & $478 * * *$ & 544 & 555 & $1.24(1.17 ; 1.31)^{* * * *}$ & 55.2 & 53.0 \\
\hline $25-64$ & 115 & 129 & 277 & $350 * * * *$ & $2.69(2.59 ; 2.79)^{* * * *}$ & 70.8 & 74.3 \\
\hline Twente & 2011 & 2016 & 2011 & 2016 & & 2011 & 2016 \\
\hline Total & 48 & $101 * * *$ & 175 & $\left.16\right|^{*}$ & $2.29(1.99 ; 2.58)^{* * * *}$ & 78.6 & 61.4 \\
\hline Men & 59 & $107 * * *$ & 120 & $109 *$ & 1.33 (I.1 I; I.54)* & 67.1 & 50.3 \\
\hline Women & 36 & $95 * * *$ & 233 & 216 & $3.89(3.45 ; 4.34)^{\text {**k* }}$ & 86.8 & 69.5 \\
\hline $15-24$ & 125 & $289 * * *$ & 358 & $228 * * *$ & I.4I (0.97; I.85) & 74.2 & 44.1 \\
\hline $25-64$ & 29 & $55^{* * *}$ & $|3|$ & 144 & $3.27(3.07 ; 3.47)^{\text {**k* }}$ & 81.8 & 72.3 \\
\hline Maastricht & 2011 & 2016 & 2011 & 2016 & & 2011 & 2016 \\
\hline Total & 115 & $161 * * *$ & 174 & 159 & $1.22(1.04 ; 1.4 \mathrm{I})^{*}$ & 60.1 & 49.7 \\
\hline Men & 116 & 149* & 122 & 116 & $0.92(0.78 ; 1.06)$ & 51.4 & 43.7 \\
\hline Women & 115 & $|7| * * *$ & 225 & 200 & 1.49 (I.28; I.7I) $)^{* *}$ & 66.1 & 53.8 \\
\hline $15-24$ & 259 & $419 * * *$ & 268 & $205^{*}$ & $0.72(0.42 ; 1.03)$ & 50.9 & 32.9 \\
\hline $25-64$ & 72 & 76 & 146 & 143 & 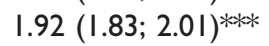 & 66.8 & 65.3 \\
\hline N-NL & 2011 & 2016 & 2011 & 2016 & & 2011 & 2016 \\
\hline Total & 52 & $69 * * *$ & 242 & $228^{* *}$ & $4.10(3.96 ; 4.23)^{* * * *}$ & 82.4 & 76.9 \\
\hline Men & 42 & $58 * * *$ & 146 & 145 & $3.16(3.03 ; 3.29)^{* * * * *}$ & 77.8 & 71.5 \\
\hline Women & 62 & $80 * * *$ & 341 & $314 * * * *$ & $4.76(4.62 ; 4.89)^{\text {**k* }}$ & 84.6 & 79.8 \\
\hline $15-24$ & 157 & $25 \mid * * *$ & 526 & $420 * * * *$ & 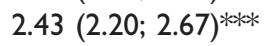 & 77.0 & 62.6 \\
\hline $25-64$ & 27 & 23 & 174 & 180 & $7.43(7.35 ; 7.52)^{\text {**** }}$ & 86.7 & 88.6 \\
\hline
\end{tabular}

GP: general practitioner; N-NL: Northeast-Netherlands; RR: relative risk; SHC: sexual health centre.

${ }^{\mathrm{a}}$ Test for trend in test rate.

${ }^{\mathrm{b}} \mathrm{RR}$ adjusted for study year, ref $=\mathrm{SHC}$.

${ }^{\mathrm{C}}$ The first and last year with available data is presented.

*Significant with $\mathrm{p}<0.05$; **significant with $\mathrm{p}<0.0$ I; ***significant with $\mathrm{p}<0.000$ I.

links. ${ }^{11}$ This observed difference between areas varying in urbanization is in line with studies in the United Kingdom and Australia. ${ }^{12-15}$ Notably, population numbers and urbanization are only slightly lower in Rotterdam as compared to Amsterdam, but SHC test rates were much lower. The SHC of Amsterdam has a long history (since 1986) and a high familiarity, while the SHC at the Rotterdam PHS was established more recently (2009). ${ }^{16,17}$

In addition to logistic aspects, regional differences in population characteristics, sexual risk behaviours and attitudes towards STI testing may explain the observed variation in test rate and GP contribution. ${ }^{2,18}$ In Amsterdam, an estimated $10 \%$ of the male population is mainly or exclusively attracted to men, while this is
$4 \%$ on a national level. ${ }^{19-21}$ The percentage of highly educated people is also higher in Amsterdam (44\%) compared to Rotterdam (29\%) and the national level (29\%) (CBS; http://www.cbs.nl). Both MSM and people with a high educational level are known to test more frequently for STIs. ${ }^{2,19}$

GP contribution decreased over time in all regions except Rotterdam, due to an increase in SHC test rate and a slight decrease in GP test rate. In Rotterdam, both rates increased. An increasing trend in the number of SHC consultations was also observed in national-level data. ${ }^{2}$ In addition to anonymity and greater perceived expertise of SHCs as compared to the $\mathrm{GPs},{ }^{22}$ an important consideration for choosing between providers likely includes costs of STI testing. ${ }^{19}$ 
Table 2. Trends and difference in urogenital Chlamydia trachomatis positivity rate between SHCs and GPs for the total population and by gender and age group in Amsterdam, Rotterdam, Twente, Limburg and N-NL, 20II-2016.

\begin{tabular}{|c|c|c|c|c|c|c|c|}
\hline \multirow[b]{3}{*}{ Amsterdam } & \multicolumn{2}{|l|}{$\mathrm{SHC}$} & \multicolumn{3}{|l|}{ GP } & \multicolumn{2}{|c|}{ Relative contribution GP } \\
\hline & \multicolumn{2}{|c|}{$\begin{array}{l}\text { Positivity } \\
\text { rate }(\%)^{a, b}\end{array}$} & \multicolumn{2}{|c|}{$\begin{array}{l}\text { Positivity } \\
\text { rate }(\%)^{a, b}\end{array}$} & \multirow[t]{2}{*}{$\operatorname{RR}(95 \% \mathrm{Cl})^{\mathrm{c}}$} & \multicolumn{2}{|l|}{$(\%)$} \\
\hline & 2011 & 2016 & 2011 & 2016 & & 2011 & 2016 \\
\hline Total & 9.7 & 10.1 & 5.9 & $7.9 * * *$ & $0.72(0.64 ; 0.8 \mathrm{I})^{* * * *}$ & 47.8 & 41.8 \\
\hline Men & 9.8 & 8.6 & 7.6 & $10.0 * * *$ & $1.00(0.88 ; 1.11)$ & 38.7 & 39.4 \\
\hline Women & 9.5 & $11.9 *$ & 5.2 & $6.9 * * *$ & $0.59(0.52 ; 0.66)^{* * *}$ & 55.8 & 43.7 \\
\hline $15-24$ & 13.3 & 14.4 & 12.2 & $14.7 * * *$ & $1.03(0.97 ; 1.08)$ & 42.5 & 26.7 \\
\hline $25-65$ & 7.3 & 6.4 & 4.2 & $6.4 * * *$ & $0.78(0.61 ; 0.95)^{* *}$ & 52.7 & 58.4 \\
\hline Rotterdam $^{\text {d }}$ & 2011 & 2016 & 2012 & 2015 & & 2012 & 2015 \\
\hline Total & 11.4 & 13.6 & 11.0 & 11.2 & $0.90(0.84 ; 0.96)^{* *}$ & 61.0 & 63.8 \\
\hline Men & 10.0 & $1 \mathrm{I} .4$ & 14.6 & 13.7 & $1.32(1.24 ; 1.39)^{* * * *}$ & 57.6 & 58.7 \\
\hline Women & 13.1 & $17.1^{* *}$ & 9.2 & 10.0 & $0.66(0.61 ; 0.71)^{* * * *}$ & 63.9 & 67.4 \\
\hline $15-24$ & 16.5 & 19.4 & 18.8 & 18.0 & I.II (1.06; I.62)*** & 56.8 & 55.5 \\
\hline $25-65$ & 7.6 & 8.5 & 7.3 & $8.6 * *$ & $0.94(0.83 ; 1.05)$ & 67.0 & 71.8 \\
\hline Twente & 2011 & 2016 & 2011 & 2016 & & 2011 & 2016 \\
\hline Total & 11.4 & 13.2 & 12.6 & $9.4 * * *$ & $0.83(0.7 \mathrm{I} ; 0.95)^{* *}$ & 80.2 & 53.1 \\
\hline Men & 10.7 & 11.5 & 15.1 & $12.2^{* *}$ & $1.18(1.09 ; 1.28)^{* *}$ & 74.3 & 51.8 \\
\hline Women & 12.8 & 15.3 & 11.3 & $7.9 *$ & $0.60(0.44 ; 0.76)^{* * *}$ & 85.3 & 54.1 \\
\hline $15-24$ & 16.6 & 16.0 & 18.4 & $13.8 *$ & $0.92(0.85 ; 0.99)^{*}$ & 76.2 & 40.7 \\
\hline $25-65$ & 6.2 & 9.7 & 8.9 & 7.7 & $0.97(0.79 ; 1.13)$ & 86.5 & 67.4 \\
\hline Maastricht & 2011 & 2016 & 2011 & 2016 & & 2011 & 2016 \\
\hline Total & 9.7 & 12.7 & 7.0 & $10.3 * * *$ & 0.85 (0.7I; 0.99) & 50.0 & 46.4 \\
\hline Men & 9.9 & 12.0 & 7.9 & $12.1 * *$ & $1.02(0.86 ; 1.19)$ & 44.8 & 45.0 \\
\hline Women & 9.5 & 13.3 & 6.5 & $9.3^{* *}$ & $0.76(0.65 ; 0.88)^{* *}$ & 54.0 & 47.3 \\
\hline $15-24$ & 12.3 & 15.3 & 9.4 & $18.2^{* *}$ & $1.05(0.89 ; 1.20)$ & 41.1 & 32.5 \\
\hline $25-65$ & 6.9 & 8.0 & 5.7 & $6.6^{*}$ & $0.89(0.68 ; 1.10)$ & 62.5 & 69.2 \\
\hline N-NL & 2011 & 2016 & 2011 & 2016 & & 2011 & 2016 \\
\hline Total & 11.4 & $15.4^{*}$ & 9.2 & $11.4 * * *$ & $0.8 \mathrm{I}(0.74 ; 0.87)^{* * *}$ & 79.1 & 71.1 \\
\hline Men & 11.0 & 12.2 & 12.4 & $14.4 * * *$ & $1.19(1.11 ; 1.26)^{* * * *}$ & 79.9 & 74.6 \\
\hline Women & 11.7 & $17.7^{* *}$ & 7.8 & $9.9 * * *$ & $0.64(0.56 ; 0.72)^{* * *}$ & 78.6 & 68.8 \\
\hline $15-24$ & 14.4 & $19.0 *$ & 13.3 & $16.1 * * *$ & $0.95(0.87 ; 1.02)$ & 75.5 & 58.9 \\
\hline $25-65$ & 7.2 & 6.0 & 6.4 & $8.6 * * *$ & $\mathrm{I} .05(0.87 ; \mathrm{I} .23)$ & 85.3 & 91.8 \\
\hline
\end{tabular}

GP: general practitioner; N-NL: Northeast-Netherlands; RR: relative risk; SHC: sexual health centre.

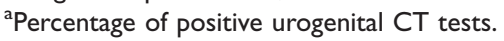

${ }^{\mathrm{b}}$ Test for trend in positivity rate.

${ }^{\mathrm{C}} \mathrm{RR}$ adjusted for year, ref $=\mathrm{SHC}$.

${ }^{\mathrm{d}}$ The first and last year with available data is presented.

*Significant with $\mathrm{p}<0.05$; **significant with $\mathrm{p}<0.0$ I; ***significant with $\mathrm{p}<0.000$ I.

Consulting a GP is covered by health insurance, but costs of STI tests are not always fully reimbursed due to a mandatory out-of-pocket payment, which increased from 170 euros in 2011 to 385 euros per year in $2016 .{ }^{23}$ Contrary, testing at SHCs is free of charge. The observed shift in contribution from GPs to SHCs was most profound among persons aged 15-24 years, who meet SHC inclusion criteria and may have shifted to avoid costs. In 2015, financial restrictions were set in place for SHCs, which resulted in stricter admission policies based on reported STI risk and symptoms. ${ }^{2}$ This is reflected most clearly in the Amsterdam SHC data, where the test rate showed an increasing trend until 2014 but dropped in 2015. This rate increased again in 2016, when local negotiations led to cheaper diagnostics enabling more consultations. ${ }^{24} \mathrm{~A}$ similar trend was observed in Twente. Logistic improvements implemented by some SHCs in the past years to allow for more consultations included online triage and sending test kits to clients instead of personal consultations. These alterations likely contributed to the finding that SHC test rates increased.

The average yearly urogenital CT positivity rate of $9.2 \%$ at GPs and $10.7 \%$ at SHCs is difficult to compare between countries as positivity rates depend on coverage and populations tested. ${ }^{25}$ For example in England, CT positivity among $15-24$ year olds in 2017 was $6.3 \%$ 

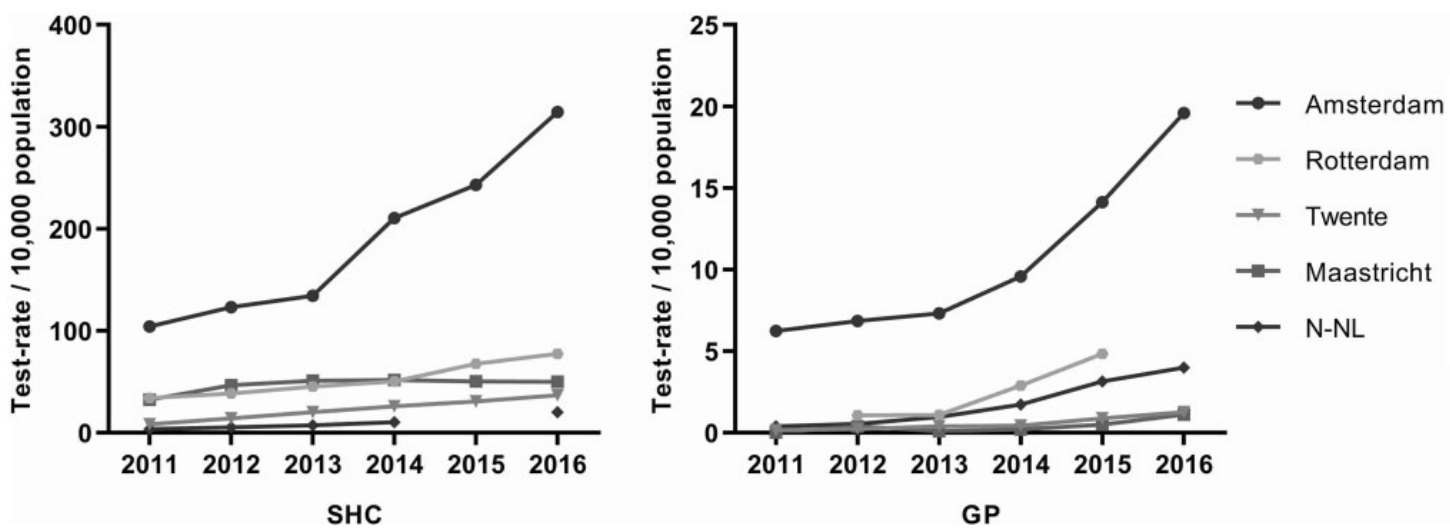

Figure 2. Annual anorectal CT test rate (15-64 years of age) at SHCs and GPs in five regions, 20II-20I6. GP: general practitioner; N-NL: Northeast-Netherlands; SHC: sexual health centre.

at GPs and $11.1 \%$ at sexual health services. This is lower than observed in our study, but contrary to the Netherlands, a national CT-screening programme is implemented in England. ${ }^{26}$ To compare rates with other countries, prevalence estimates based on nationally representative surveys would be more suitable. ${ }^{25}$

Lower urogenital CT positivity rates at GPs compared to SHCs were mainly driven by high test rates and low positivity rates among women. Women are known to generally seek health care more often compared to men and a higher percentage of women test repeatedly for STIs. ${ }^{21}$ Furthermore, GPs may particularly perform tests among women at low-risk for STIs who consult the GP for non-specific symptoms (e.g. vaginal discharge) or as part of a check-up in a routine procedure (e.g. IUD-insertion). Urogenital CT positivity rates at SHCs increased over the study period, partially explained by stricter prioritization of clients at highest risk for STI, e.g. those with symptoms or notified for STI exposure. Although positivity was largely similar across regions in $2011(10-11 \%)$, more divergence emerged up to $2016(10-15 \%)$ which may be a result of regional differences in SHC capacity and prioritization of clients. ${ }^{17}$ Increases in GP positivity rates in some regions could be indicative of more selective testing practices by GPs or be due to increased cost of testing which can be a barrier for people at low-risk. Remarkably, CT positivity at Rotterdam GPs remained stable at a high level $(11 \%)$ with increasing test rates. More client-level data are needed to further interpret these trends, inform policies and assess the need for interventions regarding people's access to and utilization of both providers.

Anorectal CT testing by GPs increased over the study period and was slightly higher compared to previous reports, ${ }^{9,27}$ which could be due to increased efforts to inform GPs about extragenital testing policies. Nevertheless, it remains far from the level of anorectal testing at SHCs. SHCs cater a high-risk population, who may report anorectal sex more frequently compared to the GP population. Yet, anal sex practices were reported by $13 \%$ in a Dutch national population survey, ${ }^{19}$ and it seems likely that GPs ask less about sexual practices than SHCs do.

A major strength of our study is that the use of laboratory data allows for an objective comparison between test providers. As the aim of this study was to compare the consultations on 'providers' level, aggregated data were sufficient. Furthermore, with laboratory data we could calculate GP test rates and positivity rates, which is not possible with the current Nivel Primary Care Database. ${ }^{2}$ Regional surveillance of STI testing rates and diagnoses of GPs and SHCs are essential to monitor effects of policy changes. We obtained data covering more than $80 \%$ of all GPs in participating regions.

There are some limitations to address. First, coverage of the GP data was estimated by PHSs or laboratories. ${ }^{9,10}$ This coverage should be interpreted with a $5 \%$ margin, and overestimation of coverage would result in an underestimation of GP contribution and vice versa. Second, it is unknown whether all patients consulting the GP for an STI consultation were tested urogenitally for CT. Our GP data may therefore underestimate total GP STI consultations. Third, more detailed patient-level information would have provided more insight into time trends and regional differences. For example, the proportion of MSM among all men affects test rates as MSM on average test more frequently. ${ }^{2,19}$ In addition, MSM more often test CT positive at extragenital sites compared to heterosexual men and $\mathrm{CT}$ infections are found solely extragenitally in more than half of the cases. ${ }^{28}$ Moreover, retesting rates are higher at SHCs compared to GPs, ${ }^{29}$ which implicates that our test rates may be higher than consultation rates at person-level at SHCs compared 
to GPs. Lastly, data of STI testing by specialists in hospitals and online self-test providers were not available. ${ }^{27}$ An evaluation of Dutch online self-test providers concluded that in 2015 between 10 and $15 \%$ of all CT testing took place using self-(sample) tests. ${ }^{30}$ Limited accessibility of SHC clinics and barriers to testing at the GP may result in an increasing use of selftests, especially among young people. ${ }^{30}$

Using urogenital CT tests as a proxy, our results showed that GPs in the Netherlands performed the majority of STI consultations, although their relative contribution decreased due to an increase in SHC test rates and a decrease in GP test rates. This shift was mainly observed among those aged 15-24 years, who qualify for free-of-charge testing at SHCs. The increasing demand for test services cannot be entirely covered by SHCs, as budgetary limitations require SHCs to increasingly focus on high-risk groups. Insight into characteristics and risk behaviour of individuals testing at the GP is needed to guide interventions and programmes aimed at optimizing STI care by GPs. Continued focus on good quality, low-threshold STI care at GPs is warranted.

\section{Authors' contribution}

JVB initiated the study. KG, MK, AH, AO, WN, ND, CH, HG, AM, FK and CK collected the data. JVB, IS and KG designed the study, supported by all other co-authors. IS analysed and interpreted the data and drafted the manuscript. All authors were involved in the data interpretation and contributed to drafting and revision of the paper. All authors read and approved the final manuscript.

IS accepts full responsibility for the conduct of the study, had access to the data and controlled the decision to publish. The corresponding author attests that all listed authors meet authorship criteria and that no others meeting the criteria have been omitted.

IS declares that this manuscript is an honest, accurate and transparent account of the study being reported, no important aspects of the study have been omitted and any discrepancies from the study as planned have been explained.

\section{Acknowledgements}

The authors thank Drs Juliën Wijers, Dr Geneviève van Liere and Dr Petra Wolffs for their support in data collection, Drs Charlotte Arguedas Flores for her involvement in the design of the study, Dr Jan van de Kassteele for his advice on the statistical analysis and Dr Birgit van Benthem for her constructive comments on the manuscript.

\section{Data accessibility statement}

The dataset generated and analysed during this study are not publicly available. The dataset may be obtained upon reasonable request from the corresponding author after permission of all parties involved.

\section{Declaration of conflicting interests}

The authors declared no potential conflicts of interest with respect to the research, authorship, and/or publication of this article.

\section{Funding}

The authors received no financial support for the research, authorship, and/or publication of this article.

\section{ORCID iDs}

IAL Slurink (D) https://orcid.org/0000-0002-3310-0329

HM Gotz (D) https://orcid.org/0000-0002-1236-6224

\section{Supplemental material}

Supplemental material for this article is available online.

\section{References}

1. World Health Organization (WHO) Report on global sexually transmitted infection surveillance, 2018. Geneva: World Health Organization, 2018.

2. Visser M, van Aar F, Op de Coul ELM, et al. Sexually transmitted infections in the Netherlands in 2017. Bilthoven: Centre for Infectious Disease Control National Institute for Publich Health and the Environment (RIVM), 2018.

3. van der Velden LFJ, Kasteleijn A and Kenens RJ. Cijfers uit de registratie van huisartsen: peiling 2016. Utrecht: NIVEL, 2017 (in Dutch).

4. Rijksinstituut voor Volksgezondheid en Milieu (RIVM). Draaiboek Seksuele gezondheid, het consult Deeldraaiboek 6: Testbeleid (in Dutch), https://ci.rivm. $\mathrm{nl} /$ draaiboeken/consult-seksuele-gezondheid (2015, accessed 15 October 2018).

5. van Bergen JE, Kerssens JJ, Schellevis FG, et al. Sexually transmitted infection health-care seeking behaviour in the Netherlands: general practitioner attends to the majority of sexually transmitted infection consultations. Int $J$ STD AIDS 2007; 18: 374-379.

6. van den Broek IV, Verheij RA, van Dijk CE, et al. Trends in sexually transmitted infections in the Netherlands, combining surveillance data from general practices and sexually transmitted infection centers. BMC Fam Pract 2010; 11: 39.

7. Suijkerbuijk AW, van den Broek IV, Brouwer HJ, et al. Usefulness of primary care electronic networks to assess the incidence of chlamydia, diagnosed by general practitioners. BMC Fam Pract 2011; 12: 72.

8. van Bergen J, Dekker JH, Boeke AJP, et al. NHGStandaard Het soa-consult (Eerste herziening). E Huisarts Wet 2013; 56: 450-463 (in Dutch).

9. Kampman CJG, Koedijk FHD, Hondelink IC, et al. Chlamydiatesten in Twente; naar de huisarts of GGD? Infect Bull 2016; 27: 99-102 (in Dutch).

10. Wijers J, van Liere G, Hoebe C, et al. Test of cure, retesting and extragenital testing practices for Chlamydia trachomatis and Neisseria gonorrhoeae among general 
practitioners in different socioeconomic status areas: a retrospective cohort study, 2011-2016. PLoS One 2018; 13: e0194351.

11. Olonilua O, Ross JD, Mercer C, et al. The limits of health-care seeking behaviour: how long will patients travel for STI care? Evidence from England's 'Patient Access and the Transmission of Sexually Transmitted Infections' ('PATSI') study. Int J STD AIDS 2008; 19: 814-816.

12. Wetten S, Mohammed H, Yung M, et al. Diagnosis and treatment of chlamydia and gonorrhoea in general practice in England 2000-2011: a population-based study using data from the UK clinical practice research datalink. BMJ Open 2015; 5: e007776.

13. Santella AJ, Pollack A, Harrison C, et al. Management rates of sexually transmissible infections by Australian general practitioners, 2000-2012. Sex Health 2014; 11 : 52-57.

14. Sadler KE, Low N, Mercer CH, et al. Testing for sexually transmitted infections in general practice: cross-sectional study. BMC Public Health 2010; 10: 667-611.

15. Bourne C, Lam M, Selvey C, et al. Changing pattern of sexually transmissible infections and HIV diagnosed in public sexual health services compared with other locations in New South Wales, 2010? Sex Health 2018; 15: 366-369.

16. van Oeffelen AA, van den Broek IV, Doesburg M, et al. Ethnic and regional differences in STI clinic use: a Dutch epidemiological study using aggregated STI clinic data combined with population numbers. Sex Transm Infect 2017; 93: 46-51.

17. Gotz HM, van Oeffelen LA, Hoebe C, et al. Regional differences in chlamydia and gonorrhoeae positivity rate among heterosexual STI clinic visitors in the Netherlands: contribution of client and regional characteristics as assessed by cross-sectional surveillance data. BMJ Open 2019; 9: e022793.

18. Trienekens SC, van den Broek IV, Donker GA, et al. Consultations for sexually transmitted infections in the general practice in the Netherlands: an opportunity to improve STI/HIV testing. BMJ Open 2013; 3: e003687.

19. de Graaf H and Wijsen C. Seksuele gezondheid in Nederland 2017. Utrecht: Rutgers, 2017 (in Dutch).

20. van den Boom W, Cremer $\mathrm{S}$ and Dijkshoorn $\mathrm{H}$. Gezondheid in Beeld. Resultaten Amsterdamse Gezondheidsmonitor 2016. Homoseksuele mannen \& lesbische of biseksuele vrouwen in Amsterdam (in Dutch), https://www.ggd.amsterdam.nl/beleid-onderzoek/ gezondheidsmonitors/amsterdamse-0/ (2016, accessed 15 October 2018).
21. Visser M, van Aar F, Koedijk FDH, et al. Repeat Chlamydia trachomatis testing among heterosexual STI outpatient clinic visitors in the Netherlands: a longitudinal study. BMC Infect Dis 2017; 17: 782.

22. Llewellyn C, Pollard A, Miners A, et al. Understanding patient choices for attending sexually transmitted infection testing services: a qualitative study. Sex Transm Infect 2012; 88: 504-509.

23. Ministery of Health, Welfare and Sport. Healthcare in the Netherlands. The Hague: Ministry of Health, Welfare and Sport, https://www.government.nl/docu ments/leaflets/2016/02/09/healthcare-in-the-netherlands (2018, accessed 15 October 2018).

24. GGD Amsterdam. Algemeen jaarverslag GGD Amsterdam 2016 (in Dutch). Amsterdam: Municipal Public Health Service Amsterdam, https://www.ggd. amsterdam.nl/ggd/publicaties/jaarverslagen/ (2016, accessed 15 October 2018).

25. van den Broek IV, Sfetcu O, van der Sande MA, et al. Changes in chlamydia control activities in Europe between 2007 and 2012: a cross-national survey. Eur J Public Health 2016; 26: 382-388.

26. Public Health England. Sexually transmitted infections and screening for chlamydia in England, 2018. Health Protection Report. Volume 11 Number 20. 9 June 2017, https://assets.publishing.service.gov.uk/government/ uploads/system/uploads/attachment_data/file/617025/ Health_Protection_Report_STIs_NCSP_2017.pdf (2017, accessed 18 September 2019).

27. den Heijer CD, van Liere GA, Hoebe CJ, et al. Who tests whom? A comprehensive overview of Chlamydia trachomatis test practices in a Dutch region among different STI care providers for urogenital, anorectal and oropharyngeal sites in young people: a cross-sectional study. Sex Transm Infect 2016; 92: 211-217.

28. van Liere GA, Hoebe CJ and Dukers-Muijrers NH. Evaluation of the anatomical site distribution of chlamydia and gonorrhoea in men who have sex with men and in high-risk women by routine testing: cross-sectional study revealing missed opportunities for treatment strategies. Sex Transm Infect 2014; 90: 58-60.

29. Dukers-Muijrers NH, van Liere GA and Hoebe CJ. Re-screening Chlamydia trachomatis positive subjects: a comparison of practices between an STI clinic, general practitioners and gynaecologists. Sex Transm Infect 2013; 89: 25-27.

30. den Daas C, Sukel B, Bos H, et al. Evaluation and enumeration of online test providers for sexually transmitted infections, specifically chlamydia, in the Netherlands. Sex Transm Infect 2019; 95: 380-385. 